\title{
Diffusion-Weighted Imaging of Breast Cancer: Correlation of the Apparent Diffusion Coefficient Value with Pathologic Prognostic Factors
}

\author{
Şehnaz Tezcan ${ }^{1}$ (1), Nihal Uslu² (D), Funda Ulu Öztürk² (D), Eda Yılmaz Akçay ${ }^{3}$ (1), Tugan Tezcaner ${ }^{4}$ (1) \\ ${ }^{1}$ Department of Radiology, Koru Hospital, Ankara, Turkey \\ ${ }^{2}$ Department of Radiology, Başkent University School of Medicine, Ankara, Turkey \\ ${ }^{3}$ Department of Pathology, Başkent University School of Medicine, Ankara, Turkey \\ ${ }^{4}$ Department of General Surgery, Başkent University School of Medicine, Ankara, Turkey
}

\begin{abstract}
Objective: The aim was to evaluate relationship between apparent diffusion coefficient (ADC) values with pathologic prognostic factors in breast carcinoma (BC).

Materials and Methods: 83 patients were enrolled in this study. Prognostic factors included age, tumor size, expression of estrogen receptor (ER) and progesterone receptor (PR), human epidermal growth factor receptor 2 (HER2), nuclear grade (NG), lymph node involvement and histologic type. The relationship between ADC and prognostic factors was determined using Independent sample t-test, ANOVA, Pearson correlation and relative operating characteristics (ROC) analysis.

Results: There was no significant difference between ADC and prognostic factors, including age, tumor size, ER, HER2 and histologic type. The PRpositive tumors $(\mathrm{p}=0.03)$ and axillary lymph node involvement $(\mathrm{p}=0.000)$ showed a significant association with lower ADC values. The ADC values were significantly lower in high-grade tumors than low-grade tumors $(\mathrm{p}=0.000)$. ROC analysis showed an optimal ADC threshold of $0.66(\times 10-3 \mathrm{~mm} 2 / \mathrm{s})$ for differentiating low-grade tumors from high-grade tumors (sensitivity, $85.5 \%$; specificity, $81 \%$; area under curve, 0.90 ).

Conclusion: The lower $\mathrm{ADC}$ values of $\mathrm{BC}$ were significantly associated with positive expression of $\mathrm{PR}, \mathrm{LN}$ positivity and high-grade tumor. Especially, $\mathrm{ADC}$ values were valuable in predicting NG subgroups.

Keywords: Breast cancer, diffusion-weighted imaging, apparent diffusion coefficient, prognostic factors

Cite this article as: Tezcan Ş, Uslu N, Ulu Öztürk F, Yılmaz Akçay E, Tezcaner T. Diffusion-Weighted Imaging of Breast Cancer: Correlation of the Apparent Diffusion Coefficient Value with Pathologic Prognostic Factors. Eur J Breast Health 2019; 15(4): 262-267.
\end{abstract}

\section{Introduction}

Prognostic factors including axillary lymph node (LN) involvement, tumor size, nuclear grade (NG), Ki-67, estrogen receptor (ER), progesterone receptor (PR) and human epidermal growth factor receptor 2 (HER2) have been used to determine the prognosis and appropriate treatment options before or following surgery in breast cancer $(1,2)$. Magnetic resonance imaging (MRI) is widely used for the evaluation of morphologic characteristics and contrast enhancement patterns of BC. The diffusion-weighted image (DWI) is a technique which analyze random Brownian motion of water molecules in tissues. DWI also yields quantitative information by using apparent diffusion coefficient (ADC) maps which shows the tumor cellularity. Several studies have shown an inverse correlation between tumor cellularity and $\mathrm{ADC}$ values (2-6). As a result of this, ADC value has been used for differentiation of malignant tumors from benign lesions and determination of aggressiveness of a tumor. The possible relationship between pathologic prognostic factors and ADC values may be helpful in evaluating the treatment response by ADC values. The majority of the studies performed up to the present evaluated the association between ADC values and pathological prognostic factors in patients with BC (1, 7-11). However, the results which have been reported by previous studies were inconclusive and controversial. The purpose of this study was to evaluate the ADC values of invasive $\mathrm{BC}$ and investigate whether the use of DWI for ADC values could provide information about the prognostic factors in $\mathrm{BC}$ including age, tumor size, LN, NG, histologic type, ER, PR and HER2. 


\section{Material and Methods}

\section{Patient selection}

The Institutional Review Board of Baskent University Hospital approved this retrospective study. Informed consent was not received due to the retrospective nature of the study. We enrolled 111 consecutive patients, who underwent MR imaging of the breast including DWI at our institute between April 2011 to December 2016, who were subsequently proven histopathologically to have BC. We excluded 28 patients, including 9 who received neoadjuvant chemotherapy and 19 with ductal carcinoma in situ or invasive foci of less than $1 \mathrm{~cm}$ (because of difficulty in drawing region of interest and poor reliability of signal intensity of the ADC map). Ultimately, 83 patients with a total of 83 breast cancers including 69 with invasive ductal carcinoma not otherwise specified (IDC NOS), 7 with invasive lobular carcinoma (ILC), 5 with invasive micropapillary carcinoma (IMPC) and 2 with invasive papillary carcinoma (IPC) were enrolled in this study.

\section{The MRI protocol}

All patients were examined using dynamic contrast-enhanced MRI (DCE-MRI) and DWI.MRI was performed with 1.5 Tesla MR (Siemens Magnetom Avanto, Erlangen, Germany) by using a dedicated breast coil while the patient was in prone position. Standard protocols for breast imaging, such as axial scout images, precontrast axial T1weighted (TR/TE, 450/9.6; matrix, 257x384; NEX, 2; slice thickness, $4 \mathrm{~mm}$; acquisition time, $2.17 \mathrm{~s}$ ) and T2-weighted (TR/TE, 5600/59; matrix, 314x320; NEX, 2; slice thickness, $4 \mathrm{~mm}$; acquisition time, $2.55 \mathrm{~s}$ ) were performed. Both before and after intravenous contrast material injection, 6 sequential fat-suppressed 3D T1-weighted images were obtained, and subtraction was performed. A bolus dose of gadoversetamide was injected intravenously at a dose of $0.1 \mathrm{mmol} / \mathrm{kg}$ of body weight. The scanning parameters for dynamic contrast-enhanced MRI were TR/TE, 4.43/1.73; matrix, 336x448; NEX, 1; slice thickness, $1.2 \mathrm{~mm}$; flip angle, $10^{\circ}$; FOV, $3.4 \times 3.4 \mathrm{~cm}$; acquisition time, 60 $s$, respectively. Prior to the dynamic analysis, echo-planar images were obtained with diffusion gradients in the $\mathrm{x}, \mathrm{y}$ and $\mathrm{z}$ planes at $\mathrm{b}$ values of 0 and $500 \mathrm{~s} / \mathrm{mm}^{2}$. The DWI sequences were obtained with the following parameters: TR/TE, 8700/109; matrix, 96x192; NEX, 2; slice thickness, $4 \mathrm{~mm}$; acquisition time, $3.38 \mathrm{~s}$. (Grappa). The ADC maps were created automatically. Calculations were made based on mean ADC maps of the circular sampling region of interest (ROI), with care taken to perform measurements in solid areas rather than necroticl cystic areas and visual artifacts. We placed three circular ROIs of $20 \pm 2$ $\mathrm{mm}^{2}$ within the tumor after referring to DCE-MRI for verification of the lesion boundaries on the ADC map. We calculated the average of the ADC values for all three ROIs within the tumor. All MRI studies were examined by the same experienced radiologist. Figure 1 show symbolic images.

\section{Prognostic Factors}

The histological grade of $\mathrm{BC}$ was assessed by using the modified criteria of Bloom and Richardson grading system which classify tumors due to the amount of gland formation, pleomorphism and mitotic activity. The grades ranged from 1 to 3 points with a total score of 3-5 representative of grade 1 (NG1), a total score of 6 or 7 representative of grade 2 (NG2) and a total score of 8 or 9 representative of grade 3 (NG3). NG was also divided into two groups which were low-grade tumors (NG1 and NG2) and high-grade tumors (NG3). Tumor size, defined as the largest diameter of the primary breast tumor was obtained from the DCE-MRI. In this study tumor size was classified under three categories ( $\leq 20 \mathrm{~mm}, 21-50 \mathrm{~mm}$ and $>50 \mathrm{~mm}$ ). Immunohistochemistry was used to evaluate the expression of the molecular markers including ER, PR and HER2. The status ER and PR was considered as positive if expression was $10 \%$ or more. The intensity of HER 2 was scored as 0 to $3+$. Scores of 0 and $1+$ were classified as HER2-negative, and scores of $3+$ were defined as HER2-positive by immunohistochemistry. The lesions with a HER2 expression of 2+ were studied by fluorescent in situ hybridization to determine the HER2 gene amplification. Axillary lymph node specimens, obtained from lymph node dissection, were analyzed by the pathologist with more than 10 years' experience. The histologic types of BCs, were classified according to the WHO classification, were obtained from our database.

\section{Statistical Analysis}

Statistical analyses were performed using the Statistical Package for Social Sciences version 22.0 (IBM Corp.; Armonk, NY, USA). The Kolmogorov-Smirnov test was used to analyze the normal distribution of data. The ADC values were compared according to the ER (positive vs. negative), PR (positive vs. negative), HER2 status (positive vs. negative), NG (low-grade vs. high-grade) and LN (positive vs. negative) using the Independent sample $t$-test. We compared the ADC values with tumor size, NG subgroups and histologic types using the oneway analysis of variance (ANOVA, post-hoc). The Pearson correlation coefficient test was used to investigate the correlation between ADC values and patients' ages. In addition, we used relative operating characteristics (ROC) analysis to evaluate the association between ADC values and NG subgroups. The "p" value less than 0.05 was considered to show a significant difference.
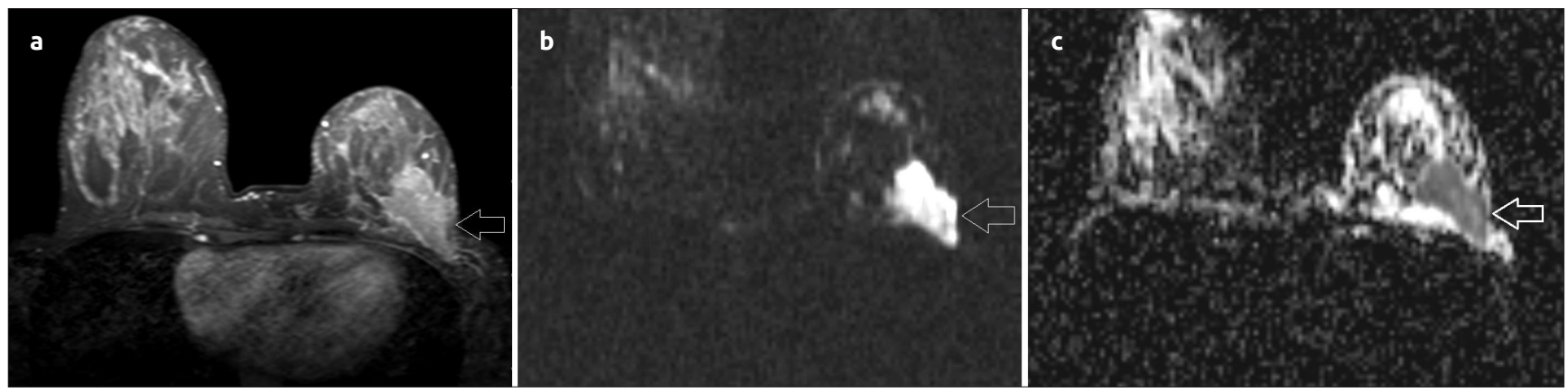

Figure 1. a-c. A 51-year-old woman with left breast cancer diagnosed as progesterone receptor (PR)-positive, estrogen receptor (ER)-positive and human epidermal growth factor receptor 2 (HER2)-negative. Dynamic contrast-enhanced MR shows heterogeneous, enhanced mass in outer quadrant of left breast (open arrow) (a). A nodule with high signal intensity was detected in the left breast on diffusion-weighted imaging (DWI) (open arrow) (b). Axial apparent diffusion coefficient (ADC) map shows low signal intensity (open arrow) in tumor (b-value: 500 $\mathrm{s} / \mathrm{mm} 2)(\mathrm{c})$ 


\section{Results}

The patients' ages ranged from 27 to 82 years (mean age: $48.3 \pm 11.3$ years), and all patients were female. There was no significant correlation between the ADC and patients' ages ( $\mathrm{p}$ value, 0.97; Pearson's correlation). The histopathological features and comparisons of mean ADC values in subgroups of prognostic factors are shown in Table 1. The size of the breast carcinomas ranged from $10 \mathrm{~mm}$ to $85 \mathrm{~mm}$ (mean size: $32.8 \pm 19.6 \mathrm{~mm})$. The majority of the lesions were ER-positive (77.1\%) and PR-positive (74.7\%). A total of 45 (54.2\%) lesions were HER2-positive, and 38 (45.8\%) were HER2-negative. Most of the tumors were IDC NOS (83.1\%). There was no significant difference be-

\section{Table 1. ADC values and Prognostic Factors in 83 Patients with Breast Cancer}

\begin{tabular}{|c|c|c|c|}
\hline $\begin{array}{l}\text { Prognostic } \\
\text { Factors }\end{array}$ & $\begin{array}{l}\text { Number of } \\
\text { Subjects (\%) }\end{array}$ & ADC Values & $\mathbf{p}$ \\
\hline $\mathrm{ER}^{\mathrm{b}}$ & & & 0.43 \\
\hline Positive & $64(77.1)$ & $0.71 \pm 0.11$ & \\
\hline Negative & 19 (22.9) & $0.74 \pm 0.1$ & \\
\hline $\mathrm{PR}^{\mathrm{b}}$ & & & 0.03 \\
\hline Positive & $62(74.7)$ & $0.70 \pm 0.11$ & \\
\hline Negative & $21(25.3)$ & $0.76 \pm 0.09$ & \\
\hline $\mathrm{HER}^{\mathrm{b}}{ }^{\mathrm{b}}$ & & & 0.71 \\
\hline Positive & $45(54.2)$ & $0.71 \pm 0.1$ & \\
\hline Negative & $38(45.8)$ & $0.72 \pm 0.12$ & \\
\hline Lymph Node ${ }^{b}$ & & & 0.000 \\
\hline Positive & $40(48.2)$ & $0.65 \pm 0.08$ & \\
\hline Negative & $43(51.8)$ & $0.78 \pm 0.09$ & \\
\hline Histological type & & & 0.28 \\
\hline IDCNOS & $69(83.1)$ & $0.73 \pm 0.1$ & \\
\hline ILC & $7(8.4)$ & $0.69 \pm 0.15$ & \\
\hline IMPC & $5(6)$ & $0.63 \pm 0.14$ & \\
\hline IPC & $2(2.4)$ & $0.69 \pm 0.06$ & \\
\hline Tumor size $(\mathrm{mm})^{c}$ & & & 0.49 \\
\hline$\leq 20$ & $29(35)$ & $0.74 \pm 0.13$ & \\
\hline $21-50$ & $40(48.2)$ & $0.71 \pm 0.09$ & \\
\hline$>50$ & $14(16.8)$ & $0.7 \pm 0.12$ & \\
\hline Nuclear Gradec & & & 0.000 \\
\hline 1 & $15(18)$ & $0.87 \pm 0.08$ & \\
\hline 2 & $47(56.6)$ & $0.72 \pm 0.07$ & \\
\hline 3 & $21(25.3)$ & $0.6 \pm 0.07$ & \\
\hline \multicolumn{4}{|c|}{$\begin{array}{l}\text { ADC: apparent diffusion coefficient; ER: estrogen receptor; PR: } \\
\text { progesterone receptor; HER2: human epidermal growth factor receptor } \\
\text { 2; IDC NOS: invasive ductal carcinoma not otherwise specified; ILC: } \\
\text { invasive lobular carcinoma; IMPC: invasive micropapillary carcinoma; IPC: } \\
\text { invasive papillary carcinoma } \\
\text { aBecause of rounding-up, the sum of percentages does not always equal } \\
100 \\
\text { bIndependent sample t-test } \\
\text { 'One-way analysis of variance }\end{array}$} \\
\hline
\end{tabular}

tween mean ADC values and prognostic factors, including ER, HER2, tumor size and histologic type. The PR-positive tumors showed significant lower ADC values than PR-negative tumors ( $\mathrm{p}=0.03)$. Lymph node status was positive in $40(48.2 \%)$ and negative in $43(51.8 \%)$ of the subjects. The LN positivity showed significant association with lower ADC values ( $p=0.000$, Figure 2). There was a significant relationship between NG subgroups and ADC values $(\mathrm{p}=0.000)$. Histologic grades were classified as low-grade tumors (NG1 and NG2) in $62(74.6 \%)$ and high-grade tumors (NG3) in 21 (25.3\%) patients. The mean ADC values were significantly lower in high-grade tumors (NG3) as compared to low-grade tumors (NG1 and NG2) ( $\mathrm{p}=0.000$, Figure 2). In addition, ROC analysis was performed to determine threshold ADC value for prediction of nuclear grade of tumors. ROC analysis revealed an optimal ADC threshold of $0.66\left(\times 10-3 \mathrm{~mm}^{2} / \mathrm{s}\right)$ for differentiating low-grade tumors (NG1 and NG2) from high grade tumors (NG3) (Figure 3A). This cut-off showed a sensitivity of $85.5 \%$ and specificity of $81 \%$ with the area under curve (AUC) of 0.90 $(\mathrm{p}=0.000)$ (Table 2, Figure 3A).

We also compared the ADC values of NG1 $(n=15)$ tumors with NG2 and NG3 tumors $(n=68)$ and found significant difference between

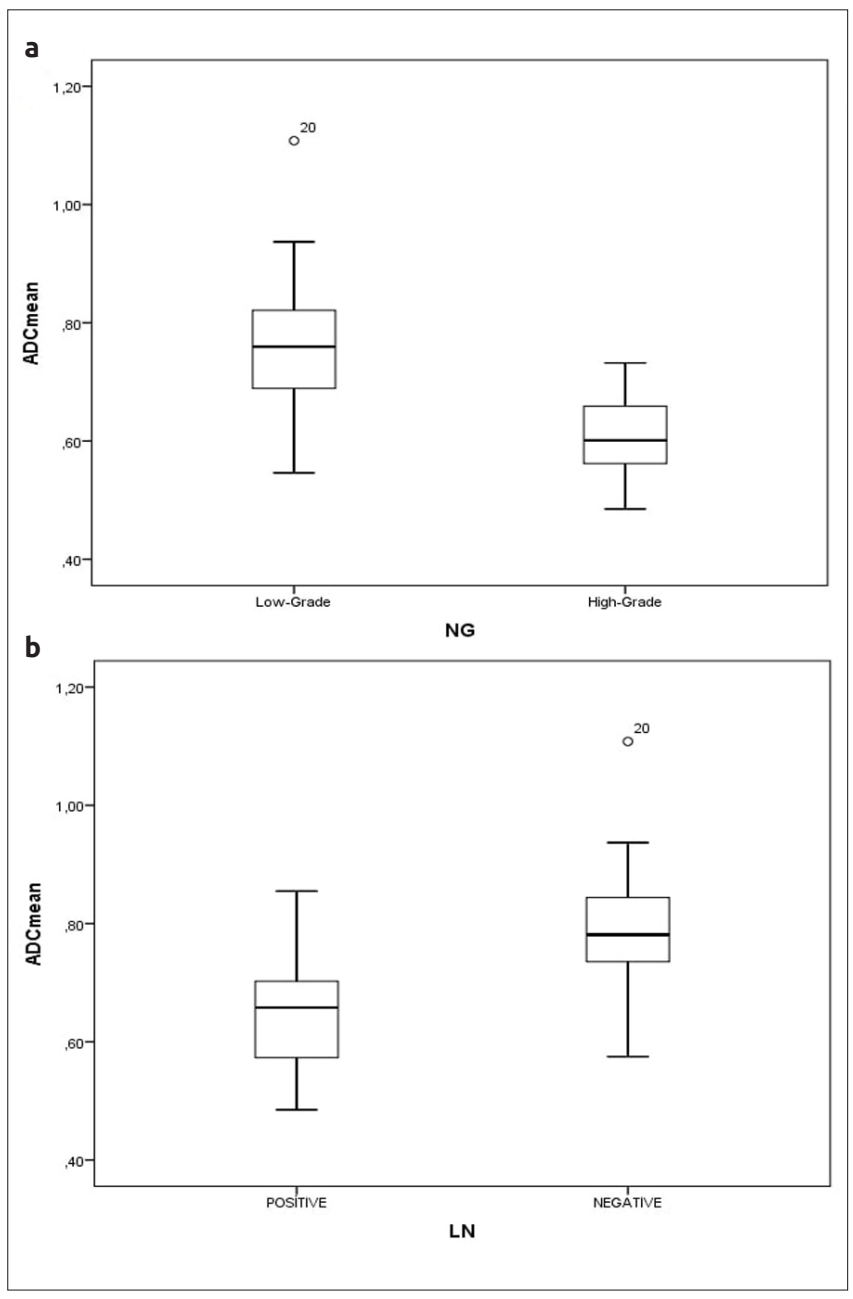

Figure 2. a, b. Boxplot showing the distribution of apparent diffusion coefficient (ADC) values of breast carcinoma according to nuclear grade (NG) (a) and axillary lymph node (LN) involvement (b). As shown, the ADC value of high-grade tumors is significantly lower than lowgrade tumors (a). ADC value of the lesions with axillary lymph node involvement is significantly lower than that of the lesions without lymph node involvement (b) 
NG1 and the other NG subgroups $(\mathrm{p}=0.000)$. ROC analysis showed an optimal ADC threshold of $0.769\left(\times 10-3 \mathrm{~mm}^{2} / \mathrm{s}\right)$ for differentiating NG1 from the other subgroups (Figure 3B). This cut-off showed a sensitivity of $100 \%$ and specificity of $80.9 \%$ with the AUC of 0.95 $(\mathrm{p}=0.000)$ (Table 3).

\section{Discussion and Conclusion}

Diffusion-weighted image is an inexpensive, noninvasive and easy method evaluating the random motion of water molecules in breast tissue. DWI has been applied for differentiating malignancy from benign tumor and evaluating treatment response in BC. Previous studies showed an inverse correlation between cellular density and ADC values, with malignancies having higher cellularity and lower ADC

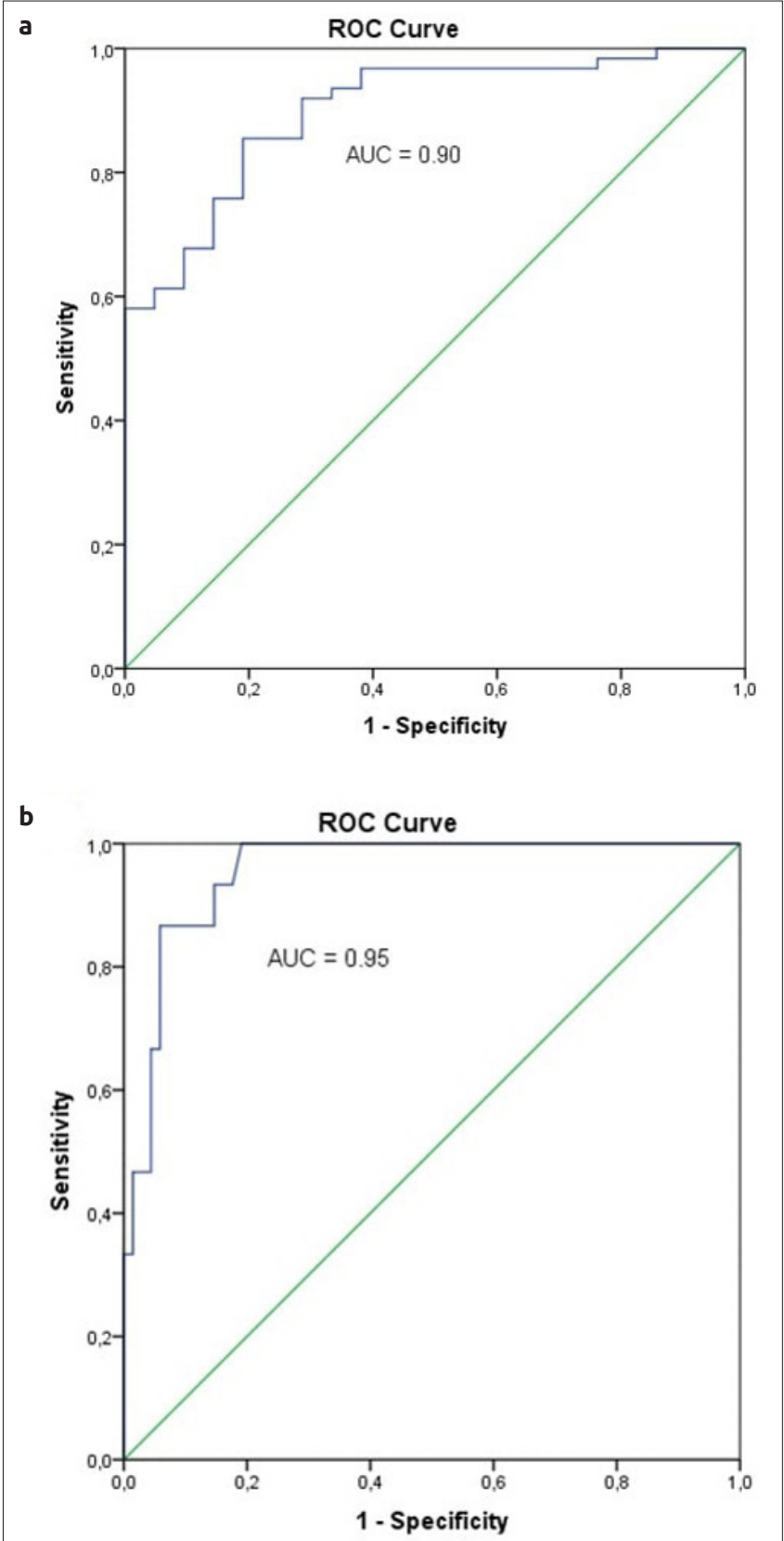

Figure 3. a, b. Relative operating characteristic curves (ROC). ROC curve in which low grade tumors (NG1 and NG2) were compared with high-grade tumors (NG3) (a). ROC curve in which NG1 was compared with $\mathrm{NG2}$ and NG3 (b) values than benign lesions $(6,12)$. Pathological prognostic factors such as tumor size, ER, PR, HER2, NG, LN status and histologic type have been used to determine the aggressiveness of tumors. Although some previous studies evaluated the relationship between the ADC values and the pathological prognostic factors, the results were controversial (1, 2, 6-9, 11-18).

Axillary lymph node involvement is one of the major prognostic factors, which affect the prognosis and survival of the patients. Previous studies revealed various controversial results in the relationship between LN status and ADC values. Because of existence of metastatic LN was associated with the aggressiveness of tumor, we hypothesized the lower ADC values would be in a significant relationship with metastatic LN. By contrast, several studies showed no association between LN metastasis and ADC values (10-12, 18, 19). However, some studies, similar to our results, showed a significant relationship between $\mathrm{LN}$ status and ADC values with LN-positive tumors having lower $\mathrm{ADC}$ values than $\mathrm{LN}$-negative tumors $(2,3)$. Interestingly, Kamitani et al. (16) reported that LN-positive tumors had significant higher $\mathrm{ADC}$ values and they considered that this might be related to the existence of micronecrosis in the LN.

Nuclear grade is a representative prognostic factor for determining tumor aggressiveness by evaluating the pleomorphism, gland maturation and mitosis which is reflective of tumor cellularity. As aforementioned

Table 2. ADC cut-off values in differentiation of low-grade (NG1 and NG2) and high-grade tumors (NG3), sensitivity and specificity values in different threshold values in the ROC analysis

\begin{tabular}{lcc} 
Threshold Value* & Sensitivity & Specificity \\
\hline 0.647 & 93.5 & 66.7 \\
0.653 & 91.9 & 71.4 \\
0.660 & 85.5 & 76.2 \\
0.664 & 85.5 & 81 \\
0.681 & 79 & 81 \\
0.688 & 75.8 & 85.7 \\
0.701 & 71 & 85.7
\end{tabular}

ADC: apparent diffusion coefficient; NG: nuclear grade; ROC: relative operating characteristics

$*\left(\times 10-3 \mathrm{~mm}^{2} / \mathrm{s}\right)$

Table 3. ADC cut-off values in differentiation of NG1 tumors and the other NG subgroups (NG2 and NG3), sensitivity and specificity values in different threshold values in the ROC analysis

$\begin{array}{lcc}\text { Threshold Value* } & \text { Sensitivity } & \text { Specificity } \\ 0.769 & 100 & 80.9 \\ 0.784 & 93.3 & 85.3 \\ 0.811 & 86.7 & 94.1\end{array}$

ADC: apparent diffusion coefficient; NG: nuclear grade; ROC: relative operating characteristics

*(x10-3 $\left.\mathrm{mm}^{2} / \mathrm{s}\right)$ 
before, the high cellularity is associated with lower ADC values in the tumor. However, some of the previous studies reported no significant association between the $\mathrm{NG}$ and $\mathrm{ADC}$ values in the $\mathrm{BC}(2,10,12,16$, $18,20)$. We found significant difference between low-grade tumors (NG1 and NG2) and high-grade (NG3) tumors similar to the study by Martincich et al. (9). According to our results, the optimal cut-off value of $0.66 \times 10-3 \mathrm{~mm}^{2} / \mathrm{s}$ in the differentiation of low-grade tumors (NG1 and NG2) from high-grade tumors (NG3) with high sensitivity and specificity has been identified (Table 2). In this study, a significant difference was also observed in ADC values between NG1 tumors and the other subgroups (NG2 and NG3), which was consistent with two previous studies $(8,19)$. Yırgın et al. (19) revealed a cut-off ADC value of $1.05\left(\times 10-3 \mathrm{~mm}^{2} / \mathrm{s}\right)$ with the sensitivity of $75 \%$ and specificity 28 $\%$ to differentiate NG1 tumors from the others. We found three optimal threshold values with the higher sensitivity and specificity which were demonstrated in Table 3 to differentiate NG1 tumors from other subgroups than the previous studies (19). We consider that ADC cut off values can be used for predicting NG subgroups.

A previous study demonstrated that the five-year BC survival rates have been found to be longer in the tumors $<2 \mathrm{~cm}$ than the tumors $>5$ $\mathrm{cm}$ (21). Our study indicated that larger tumors $(>5 \mathrm{~cm})$ had higher mean ADC values than the smaller tumors $(<5 \mathrm{~cm})$; however, the difference was not statistically significant. Nevertheless, there are some studies reporting significant association between the tumor size and ADC values with larger tumors having lower ADC values than smaller tumors $(15,22)$. However, in consistency with our study, some researches revealed that the ADC values and tumor size were not correlated $(2,10,12,17)$. This may be related to the variable amount of histologic contents such as fibrosis, necrosis, cellularity, angiogenesis or hemorrhage in the tumors.

Estrogen receptor-positive tumors are well differentiated and generally presents effective response to hormonal therapy $(23,24)$. The relationship between the ADC values and the ER status has been reported in several studies (1, 2, 9-11, 15-18). Some studies revealed that ER status was associated with high tumor cellularity which was related to the lower $\operatorname{ADC}$ values $(25,26)$. However, in our study we found no association between the ADC values and ER which is inconsistent with some previous studies $(3,9,11,12,16,17)$. We also observed significantly lower ADC values for PR-positive carcinomas as compared to PR-negative cancers $(\mathrm{p}=0.03)$. Similar to our results, some previous studies found a significant relationship between ADC values and PR expression $(1,16,17)$. Nevertheless, several studies reported no association between $\mathrm{ADC}$ values and $\mathrm{PR}$ which forms a contrast to our study $(2,10,11,18,19)$.

The overexpression of HER2 receptor was associated with epithelial cell growth and angiogenesis which may be related to the increased risk of recurrence and poor prognosis $(27,28)$. As a result of this, we hypothesized that lower ADC values may be associated with positive expression of HER2. However, we found no significant correlation between the ADC values and HER2 status in our study. Moreover, we observed that higher ADC values were more likely in HER2-positive tumors than in HER2-negative tumors. Nevertheless, this correlation was not significant. The majority of the previous studies revealed no significant relationship between ADC values and HER2 status which is consistent with our study $(9,15-17)$. However, some studies reported significantly lower ADC values for HER2-negative tumors as
We also investigated the correlation of the ADC values with age and histologic type in this study. In breast cancer, both young and advanced age may be associated with poor prognosis (29). The influence of age on prognosis is more prominent in sub-types of breast cancer. Age has a more significant impact on prognosis in luminal cancer types as compared to other sub-types of BC (30). Similar to our study, previous studies did not report a significant correlation between ADC values and patients' age $(12,19)$.

Invasive ductal carcinoma NOS is the most common type of invasive breast cancer followed by ILC, the second most common tumor. The majority of the tumors were IDC NOS ( $83 \%)$ in this study. No significant difference was observed between histologic types and ADC values in this study similar to some of the previous studies $(2,9)$. However, Kitajima et al. (15) found a significant association between the histologic type and the ADC values and stated that the ADC values of ILCs were lower as compared to IDCs.

This study has some limitations which have to be pointed out. First, it was designed as a retrospective study. Second, imaging was performed at 1.5 Tesla for evaluation of ADC values and therefore, we had to exclude the tumors $<1 \mathrm{~cm}$ to accurately measure ADC values on 1.5 Tesla MRI. Third, Ki-67 which is an important prognostic factor of BC could not have been evaluated due to the inadequate data of the subjects.

The lower $\mathrm{ADC}$ values of $\mathrm{BC}$ were related to the positive expression of PR, LN positivity and high-grade tumor. Especially, ADC values were valuable in predicting both NG1 and NG3 tumors from the other subtypes. In addition, further studies are necessary to assess the additional role of $A D C$ values in improving the detection of pathologic prognostic factors in a larger and more generalized population with prospective design.

Ethics Committee Approval: Ethics committee approval was received for this study from the ethics committee of Institutional Review Board of Baskent University Hospital (Approval Date: 09.05.2017, Approval No: KA17/143)

Informed Consent: Informed consent was not received due to the retrospective nature of the study.

Peer-review: Externally peer-reviewed.

Author Contributions: Concept - S.T., N.U., F.U.O.; Design - S.T., FUO.; Supervision - S.T., F.U.O.; Resources - S.T., N.U., F.U.O., E.Y.A., T.T.; Materials - S.T., N.U., F.U.O., E.Y.A, T.T., Data Collection and/or Processing - S.T., F.U.O.; Analysis and/or Interpretation - S.T.; Literature Search - S.T.; Writing Manuscript - S.T; Critical Review - S.T., N.U., F.U.O.

Conflict of Interest: The authors have no conflicts of interest to declare.

Financial Disclosure: The authors declared that this study has received no financial support.

\section{References}

1. Meng L, Ma P. Apparent diffusion coefficient value measurements with diffusion magnetic resonance imaging correlated with the expression levels of estrogen and progesterone receptor in breast cancer: A meta-analysis. J Cancer Res Ther 2016; 12: 36-42. (PMID: 27072207) [CrossRef]

2. Park EK, Cho KR, Seo BK, Woo OH, Cho SB, Bae JW. Additional Value of Diffusion-Weighted Imaging to Evaluate Prognostic Factors of Breast Cancer: Correlation with the Apparent Diffusion Coefficient. Iran J Radiol 2016; 13: e33133. (PMID: 27127582) [CrossRef] 
3. Henry NL, Hayes DF. Uses and abuses of tumor markers in the diagnosis, monitoring, and treatment of primary and metastatic breast cancer. Oncologist 2006; 11: 541-552. (PMID: 16794234) [CrossRef]

4. Ozmen V, Muslumanoglu M, Cabioglu N, Tuzlali S, Ilhan R, Igci A, Kecer M, Bozfakioglu Y, Dagoglu T. Increased false negative rates in sentinel lymph node biopsies in patients with multi-focal breast cancer. Breast Cancer Res Treat 2002; 76: 237-244. (PMID: 12462384) [CrossRef]

5. Chowdhury N, Pai MR, Lobo FD, Kini H, Varghese R. Interobserver variation in breast cancer grading: a statistical modeling approach. Anal Quant Cytol Histol 2006; 28: 213-218. (PMID: 16927641)

6. Woodhams R, Ramadan S, Stanwell P, Sakamoto S, Hata H, Ozaki M, Kan S, Inoue Y. Diffusion-weighted Imaging of the Breast: Principles and Clinical Applications. Radiographics 2011; 31: 1059-1084. (PMID: 21768239) [CrossRef]

7. Shin HJ, Kim HH, Shin KC, Sung YS, Cha JH, Lee JW, Son BH, Ahn $\mathrm{SH}$. Prediction of low-risk breast cancer using perfusion parameters and apparent diffusion coefficient. Magn Reson Imaging 2016; 34: 67-74. (PMID: 26523654) [CrossRef]

8. Costantini M, Belli P, Distefano D, Bufi E, Matteo MD, Rinaldi P, Giuliani M, Petrone G, Magno S, Bonomo L. Magnetic resonance imaging features in triple-negative breast cancer: comparison with luminal and HER2-overexpressing tumors. Clin Breast Cancer 2012; 12: 331-339. (PMID: 23040001) [CrossRef]

9. Martincich L, Deantoni V, Bertotto I, Redana S, Kubatzki F, Sarotto I, Rossi V, Liotti M, Ponzone R, Aglietta M, Regge D, Montemurro F. Correlations between diffusion-weighted imaging and breast cancer biomarkers. Eur Radiol 2012; 22: 1519-1528. (PMID: 22411304) [CrossRef]

10. Jeh SK, Kim SH, Kim HS, Kang BJ, Jeong SH, Yim HW, Song BJ. Correlation of the apparent diffusion coefficient value and dynamic magnetic resonance imaging findings with prognostic factors in invasive ductal carcinoma. J Magn Reson Imaging 2011; 33: 102-109. (PMID: 21182127) [CrossRef]

11. Kim EJ, Kim SH, Park GE, Kang BJ, Song BJ, Kim YJ, Lee D, Ahn H, Kim I, Son YH, Grimm R. Histogram analysis of apparent diffusion coefficient at 3.0t: Correlation with prognostic factors and subtypes of invasive ductal carcinoma. J Magn Reson Imaging 2015; 42: 1666-1678. (PMID: 25919239) [CrossRef]

12. Choi BB, Kim SH, Kang BJ, Lee JH, Song BJ, Jeong SH, Yim HW. Diffusion-weighted imaging and FDG PET/CT: predicting the prognoses with apparent diffusion coefficient values and maximum standardized uptake values in patients with invasive ductal carcinoma. World J Surg Oncol 2012; 10: 126. (PMID: 22741544) [CrossRef]

13. Colzani E, Liljegren A, Johansson AL, Adolfsson J, Hellborg H, Hall PF, Czene K. Prognosis of patients with breast cancer: causes of death and effects of time since diagnosis, age, and tumor characteristics. J Clin Oncol 2011; 29: 4014-4021. (PMID: 21911717) [CrossRef]

14. Harris L, Fritsche H, Mennel R, Norton L, Ravdin P, Taube S, Somerfield MR, Hayes DF, Bast RC Jr. American Society of Clinical Oncology 2007 update of recommendations for the use of tumor markers in breast cancer. J ClinOncol 2007; 25: 5287-5312. (PMID: 17954709) [CrossRef]

15. Kitajima K, Yamano T, Fukushima K, Miyoshi Y, Hirota S, Kawanaka Y, Miya M, Doi H, Yamakado K, Hirota S. Correlation of the SUVmax of FDG-PET and ADC values of diffusion-weighted MR imaging with pathologic prognostic factors in breast carcinoma. Eur Radiol 2016; 85: 943-949. (PMID: 27130054) [CrossRef]

16. Kamitani T, Matsuo Y, Yabuuchi H, Fujita N, Nagao M, Jinnouchi M, Yonezawa M, Yamasaki Y, Tokunaga E, Kubo M, Yamamoto H, Yoshiura T, Honda $\mathrm{H}$. Correlations between apparent diffusion coefficient values and prognostic factors of breast cancer. Magn Reson Med Sci 2013; 12: 193-199. (PMID: 23857151) [CrossRef]
17. Choi SY, Chang YW, Park HJ, Kim HJ, Hong SS, Seo DY. Correlation of the apparent diffusion coefficiency values on diffusion-weighted imaging with prognostic factors for breast cancer. Br J Radiol 2012; 85: e474e479. (PMID: 22128125) [CrossRef]

18. Kim SH, Cha ES, Kim HS, Kang BJ, Choi JJ, Jung JH, Park YG, Suh YJ. Diffusion-weighted imaging of breast cancer: correlation of the apparent diffusion coefficient value with prognostic factors. J MagnReson Imaging 2009; 30: 615-620. (PMID: 19711411) [CrossRef]

19. Kızıldağ Yırgın İ, Arslan G, Öztürk E, Yırgın H, Taşdemir N, Gemici AA, Kabul FÇ, Kaya E. Diffusion Weighted MR Imaging of Breast and Correlation of Prognostic Factors in Breast Cancer. Balkan Med J 2016; 33: 301-307. (PMID: 27308074) [CrossRef]

20. Guvenc I, Akay S, Ince S, Yildiz R, Kilbas Z, Oysul FG, Tasar M. Apparent diffusion coefficient value in invasive ductal carcinoma at 3.0 Tesla: is it correlated with prognostic factors? Br J Radiol 2016; 89: 201506. (PMID: 26853508) [CrossRef]

21. Koscielny S, Tubiana M, Lê MG, Valleron AJ, Mouriesse H, Contesso G, Sarrazin D. Breast cancer: relationship between the size of the primary tumour and the probability of metastatic dissemination. Br J Cancer 1984; 49: 709-715. (PMID: 6733019) [CrossRef]

22. Razek AA, Gaballa G, Denewer A, Nada N. Invasive ductal carcinoma: correlation of apparent diffusion coefficient value with pathological prognostic factors. NMR Biomed 2010; 23: 619-623. (PMID: 20232453) [CrossRef]

23. Davies C, Godwin J, Gray R, Clarke M, Cutter D, Darby S, McGale P, Pan HC, Taylor C, Wang YC, Dowsett M, Ingle J, Peto R. Relevance of breast cancer hormone receptors and other factors to the efficacy of adjuvant tamoxifen: patient-level meta-analysis of randomised trials. Lancet 2011; 378: 771-784. (PMID: 21802721) [CrossRef]

24. Tsai MJ, O'Malley BW. Molecular mechanisms of action of steroid/thyroid receptor superfamily members. Annu Rev Biochem 1994; 63: 451686. (PMID: 7979245) [CrossRef]

25. Black R, Prescott R, Bers K, Hawkins A, Stewart H, Forrest P. Tumor cellularity, estrogen receptors and prognosis in breast cancer. Clin Oncol 1983; 9: 311-318. (PMID: 6661854)

26. Ludovini V, Sidoni A, Pistola L, Bellezza G, De Angelis V, Gori S, Mosconi AM, Bisagni G, Cherubini R, Bian AR, Rodinò C, Sabbatini R, Mazzocchi B, Bucciarelli E, Tonato M, Colozza M. Evaluation of the prognostic role of vascular endothelial growth factor and microvessel density in stage I and II breast cancer patients. Breast Cancer Res Treat 2003; 81: 159-168. (PMID: 14572158) [CrossRef]

27. Slamon DJ, Clark GM, Wong SG, Levin WJ, Ullrich A, McGuire WL. Human breast cancer: correlation of relapse and survival with amplification of the HER-2/neu oncogene. Science 1987; 235: 177-182. (PMID: 3798106) [CrossRef]

28. Petit AM, Rak J, Hung MC, Rockwell P, Goldstein N, Fendly B, Kerbel RS. Neutralizing antibodies against epidermal growth factor and ErbB-2/ neu receptor tyrosine kinases down-regulate vascular endothelial growth factor production by tumor cells in vitro and in vivo: angiogenic implications for signal transduction therapy of solid tumors. Am J Pathol 1997; 151: 1523-1530. (PMID: 9403702)

29. Adami HO, Malker B, Holmberg L, Persson I, Stone B. The relation between survival and age at diagnosis in breast cancer. N Engl J Med 1986; 315: 559-563. (PMID: 3736639) [CrossRef]

30. Partridge AH, Hughes ME, Warner ET, Ottesen RA, Wong YN, Edge SB, Theriault RL, Blayney DW, Niland JC, Winer EP, Weeks JC, Tamimi RM. Subtype-Dependent Relationship Between Young Age at Diagnosis and Breast Cancer Survival. J Clin Oncol 2016; 34: 3308-3314. (PMID: 27480155) [CrossRef] 